\title{
MECHANICAL ANALYSIS OF MIDLINE STERNOTOMY WOUND CLOSURE
}

Walter E. McGregor, MD Dennis R. Trumble, $\mathrm{MS}^{\mathrm{b}}$

James A. Magovern, MD $^{\mathrm{b}}$
Objective: Unstable median sternotomy closure can lead to postoperative morbidity. This study tests the hypothesis that separation of the sternotomy site occurs when physiologic forces act on the closure. Methods: Median sternotomy was performed in 4 human cadavers ( 2 male) and closed with 7 interrupted stainless steel wires. The chest wall was instrumented to apply 4 types of distracting force: (1) lateral, (2) anterior-posterior, (3) rostral-caudal, and (4) a simulated Valsalva force. Forces were applied in each direction and were limited to physiologic levels $(<400$ N). Four sets of sonomicrometry crystals were placed equidistantly along the sternum to measure separation at the closure site. Results: Sternal separation occurred as a result of the wires cutting through the bone. Less force was needed to achieve $2.0-\mathrm{mm}$ distraction in the lateral direction $(220 \pm 40 \mathrm{~N})$ than in the anterior-posterior $(263 \pm 74 \mathrm{~N})$ and rostral-caudal $(325 \pm 30 \mathrm{~N})$ directions. More separation occurred at the lower end of the sternum than the upper. During lateral distraction, xiphoid and manubrial displacement averaged $1.85 \pm 0.14$ and $0.35 \pm$ $0.12 \mathrm{~mm}$, respectively. Anterior-posterior distraction caused $1.99 \pm$ $0.04-\mathrm{mm}$ xiphoid displacement and $0.26 \pm 0.12-\mathrm{mm}$ manubrial displacement. During a simulated Valsalva force, more separation occurred in the lateral $(2.14 \pm 0.11 \mathrm{~mm})$ than in the anterior-posterior $(0.46 \pm 0.29$ $\mathrm{mm})$ or rostral-caudal $(0.25 \pm 0.15 \mathrm{~mm})$ directions. Conclusions: These data suggest that sternal dehiscence can occur under physiologic loads and that improved sternal stability may be readily achieved via mechanical reinforcement near the xiphoid. Closure techniques designed to minimize wire migration into the sternum should also be developed. (J Thorac Cardiovasc Surg 1999;117:1144-50)
$\mathrm{M}$ inimally invasive thoracic incisions are gaining popularity in cardiac surgery, but most cardiac operations are still done through a midline sternotomy incision because of its versatility and familiarity to surgeons. This incision provides excellent exposure of vital chest structures, is rapidly performed, and is well

From the Department of General Surgery, Northside Medical Center, Forum Health, ${ }^{a}$ Youngstown, Ohio, and Cardiothoracic Surgery Research, Cardiovascular and Pulmonary Research Institute, and Department of Thoracic Surgery, Allegheny General Hospital, ${ }^{b}$ Pittsburgh, Pa.

Supported by the Allegheny Heart Institute, Pittsburgh, Pa.

Received for publication Dec 11, 1998; revisions requested Jan 22, 1999; revisions received Feb 10, 1999; accepted for publication Feb 16, 1999.

Address for reprints: James A. Magovern, MD, Cardiothoracic Surgery Research, CVPRI, 14th Floor, South Tower, Allegheny General Hospital, 320 East North Ave, Pittsburgh, PA 15212.

Copyright (C) 1999 by Mosby, Inc.

$0022-5223 / 99 \$ 8.00+0 \quad \mathbf{1 2 / 1 / 9 7 9 1 7}$ tolerated by most patients. However, sternotomy wound complications and prolonged healing periods are persistent problems that have not been addressed or solved in a scientific manner. ${ }^{1-4}$

Median sternotomy wound complications range from prolonged incisional pain to dehiscence and mediastinitis. These problems are often preceded by sternal instability, which has been shown to compromise wound integrity and promote bacterial infection. ${ }^{2,5,6}$ This study presents a comprehensive analysis of the stability of human sternal closure when subjected to mechanical distracting forces and to increases in intrathoracic pressure. The goal is to elucidate the mechanisms for sternal dehiscence so that improved methods for sternal closure can be developed.

\section{Methods}

Median sternotomy was performed in 4 adult human cadavers (2 male). Sternotomy closure was subjected to 4 distinct distracting forces, including a simulated Valsalva force. 
Resulting sternal motion was detected by measuring separation between the 2 halves of the sternum.

Cadaver preparation. Median sternotomy was performed with an oscillating saw and closed with No. 5 stainless steel wire that was symmetrically tightened by twisting with a large needle-driver. A total of 7 wires were placed: 2 at the manubrium and 5 around the sternum in intercostal spaces 2 to 6 . The chest wall was instrumented to apply distracting forces across the sternal closure. Brass plates were placed above and below the second, fourth, and sixth ribs bilaterally to prevent rib fracture resulting from concentration of forces at the 6 fixation points. A custom-designed rigid cage was constructed from steel piping and placed over the cadaver to provide anchor points for the application of traction forces (Fig 1). Thin steel cables (1/16-inch diameter) were attached to metal hose clamps that were secured around the brass plates near the sternal insertion. Cables on one side of the sternum were fixed directly to the steel piping. Cables on the other side were first connected to a single o-ring, then to a turnbuckle, a load-cell, and finally to the rigid cage. The turnbuckle was used to increase tension in the cable which, in turn, applied force to the sternal closure. The load cell (model LCDB-200, Omega Engineering, Inc, Stamford, Conn) was used in conjunction with a DP25 series digital indicator (Omega Engineering, Inc) to measure traction forces.

Force application techniques. Traction forces were applied along 3 mutually orthogonal lines of motion: lateral, rostral-caudal, and anterior-posterior (Fig 2). The lateral force was applied by directing the cables parallel to the short axis and perpendicular to the long axis of the sternum, as shown in Fig 1. The rostral-caudal force was generated by attaching the cables perpendicular to the short axis and parallel to the long axis of the sternum. The anterior-posterior force was applied perpendicular to both the short and long axes of the sternum.

The effect of increased intrathoracic pressures (eg, from sneezing or coughing) on the stability of the sternal closure was modeled by placing an inflatable bladder inside the chest cavity. Saline bags were purged of air, placed in the right and left pleural cavities, and attached by plastic tubing to a Harvard Apparatus 52-966 pressure transducer (Harvard Apparatus, Inc, S Natick, Mass). The transducer was used to measure intrathoracic pressure as the bladder was inflated with a Topeak JB-2G pump (Todson, Inc, Deerpark, NY).

Measurement of sternal distraction. Four pairs of piezoelectric crystal transducers were used to measure distraction of the closure site (sonomicrometer model 120, Triton Technology, Inc, San Diego, Calif). In the lateral and rostralcaudal distraction experiments, 4 pairs of crystals were placed on the anterior surface of the sternum, 1 on each side of the closure, at intervals equidistant from each other. One pair was placed on the manubrium, 2 pairs on the sternum, and 1 pair at the sternoxiphoid junction. Ultrasonic gel was placed between the crystals to provide a medium for sound wave conduction. Anterior-posterior motion was measured by placing 1 crystal of each pair face-up on one side of the sternum while the other was suspended (face down) directly

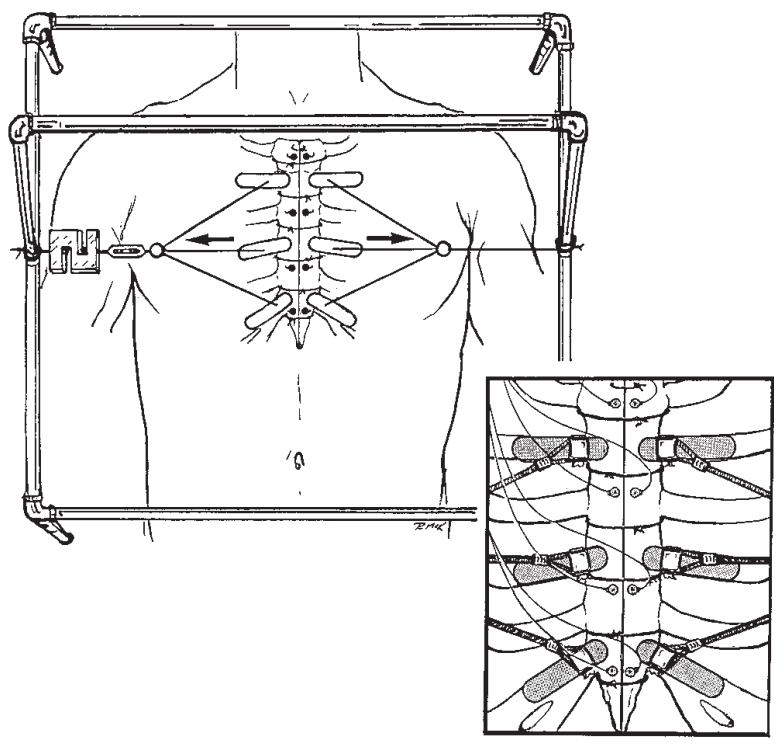

Fig 1. Experimental setup used to apply traction forces to the sternums of intact human cadavers. A rigid enclosure fashioned from steel pipe ( 0.85 -inch outer diameter) was used to provide stable anchoring points for sternal traction in 3 mutually orthogonal directions: lateral (shown here), rostral-caudal, and anterior-posterior. Force was applied through steel cables secured to the second, fourth, and sixth ribs at their insertion points and adjusted via a turnbuckle mechanism. Bone fracture was prevented by pressing each rib between 2 brass plates with the use of a small metal hose clamp (to which the cable was attached). Sternal motion was monitored by means of 4 pairs of sonomicrometry crystals and tension was measured via an S-beam load cell.

above the first via a small Allen wrench anchored to the opposite side. Vertical traction was applied to one side of the sternum such that the lower crystals were drawn toward the upper crystals. In all traction experiments, forces were applied in discrete 10-N increments (starting at a resting tension of $40 \mathrm{~N}$ ) until $2.0 \mathrm{~mm}$ of distraction was noted in at least 1 set of crystals. This end point was chosen as an amount of motion that would be clinically important and as a means to prevent the wires from fracturing the sternum and causing complete dehiscence.

Intrathoracic pressure experiments were conducted after completion of the distracting force experiments in each cadaver. Because distraction studies showed the xiphoid region of the sternum to be the least stable, all crystals were placed at the lower end of the sternum and arranged to measure motion in lateral, anterior-posterior, and rostral-caudal directions simultaneously. Intrathoracic pressure was steadily increased until $2.0-\mathrm{mm}$ motion was detected in at least 1 set of crystals.

In all cases, lateral traction experiments were performed first, followed by anterior-posterior and rostral-caudal distraction trials (in that order). Intrathoracic pressure studies were 


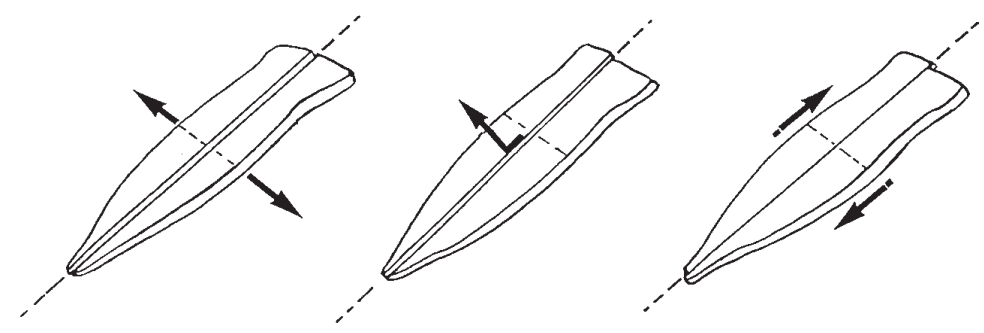

Fig 2. Schematic portrayal of traction forces applied across the sternum: left, lateral; center, anterior-posterior; and right, rostral-caudal. Arrows represent the force vectors delivered by the sternal traction apparatus depicted in Fig 1. Note that anterior-posterior motion is induced by a single vertical force vector applied to one side of the sternum.

Table I. Average motion of sonomicrometry crystal pairs $(C P)$ in response to peak traction forces $\left(F_{\text {MAX }}\right)$ applied across the sternum in 3 mutually orthogonal directions

\begin{tabular}{|c|c|c|c|}
\hline & \multicolumn{3}{|c|}{ Sternal motion at peak traction force $(\mathrm{mm})$} \\
\hline & Lateral & $\begin{array}{l}\text { Anterior- } \\
\text { posterior }\end{array}$ & $\begin{array}{l}\text { Rostral- } \\
\text { caudal }\end{array}$ \\
\hline $\mathrm{F}_{\mathrm{MAX}}(\mathrm{N})$ & $220 \pm 40$ & $263 \pm 74$ & $325 \pm 30$ \\
\hline CP 1 & $0.35 \pm 0.12$ & $0.26 \pm 0.12$ & $1.10 \pm 0.25$ \\
\hline $\mathrm{CP} 2$ & $1.12 \pm 0.35$ & $0.73 \pm 0.27$ & $1.19 \pm 0.40$ \\
\hline CP 3 & $1.55 \pm 0.32$ & $1.44 \pm 0.30^{*}$ & $1.21 \pm 0.50$ \\
\hline CP 4 & $1.85 \pm 0.14 *$ & $1.99 \pm 0.04 *$ & $1.89 \pm 0.16$ \\
\hline
\end{tabular}

Data are mean \pm SE. Four sets of crystals were placed equidistantly along the long axis of the sternum and positioned to detect the relative displacement of the sternal halves. Crystal pair 1 was stationed near the manubrium and crystal pair 4 near the xiphoid process.

*Statistically significant increase relative to crystal pair $1(P<.05)$.

performed last. Sternal wires were tightened to original tension levels after each experiment to reverse loosening produced by forced sternal motion against the twisted wire closure.

Data collection and statistical analysis. During sternal traction, crystal separations were recorded in discrete data sets, one for each load level applied. Sonomicrometry waveforms were recorded continuously during Valsalva studies. Data were digitized at a rate of 25 samples/s and stored in an IBM 300PL personal computer (data acquisition package: WinDAQ, Dataq Instruments, Akron, Ohio). Analysis of variance was performed to determine whether differences in separation existed among the 4 sternal sites monitored in the 4 cadavers (TRUE EPISTAT, Epistat Services, Richardson, Tex). Where differences were found, Bonferroni-corrected paired $t$ tests were performed to determine which sites yielded significant differences in separation distances. All summary data are expressed as mean $\pm \mathrm{SE}$.

\section{Results}

In each of the 12 traction tests conducted ( 3 per cadaver), some degree of sternal motion was detected in all 4 crystal pairs. Displacement varied with the ori- entation of the applied force and was much more pronounced near the caudal end of the sternum. No evidence of stretching, untwisting, or breaking of the wires was found. Rather, the wires moved into the bone as mechanical forces acted on the sternum.

As previously mentioned, sternal distraction was stopped when $2.0-\mathrm{mm}$ motion was detected in 1 set of crystals to prevent complete dehiscence. This occurred for lateral, anterior-posterior, and rostral-caudal forces of $220 \pm 40,263 \pm 74$, and $325 \pm 30 \mathrm{~N}$, respectively. Sternal motion was maximum near the xiphoid and minimum near the manubrium in all 4 cadavers, regardless of traction orientation (Table I). During lateral distraction, xiphoid and manubrial displacement averaged $1.85 \pm 0.14$ and $0.35 \pm 0.12 \mathrm{~mm}$, respectively $(P=$ $.0003)$. Anterior-posterior distraction caused $1.99 \pm$ $0.04-\mathrm{mm}$ xiphoid displacement and $0.26 \pm 0.12-\mathrm{mm}$ manubrial displacement $(P=.0004)$. Representative force-distraction curves (acquired from the most robust model of sternal closure tested) are shown in Fig 3.

Sternal distraction with increasing intrathoracic pressure was measured in 3 directions but was examined only near the xiphoid for reasons stated previously. Mean intrathoracic pressures of $63 \pm 21 \mathrm{~mm} \mathrm{Hg}$ produced $2.14 \pm 0.11-\mathrm{mm}$ motion in the lateral direction, but yielded only $0.46 \pm 0.29-\mathrm{mm}(P=.002)$ and 0.25 $\pm 0.15-\mathrm{mm}(P=.001)$ motion in the anterior-posterior and rostral-caudal directions, respectively. Typical intrathoracic pressure-distraction curves at the xiphoid for lateral, anterior-posterior, and rostral-caudal directions are shown in Fig 4.

\section{Discussion}

Median sternotomy is the most commonly performed incision in cardiac surgery, and stainless steel wiring continues to be the standard technique for closure. Most sternotomy incisions heal without complications, but problems persist in a small but consistent percentage of patients. These complications can be minor, 

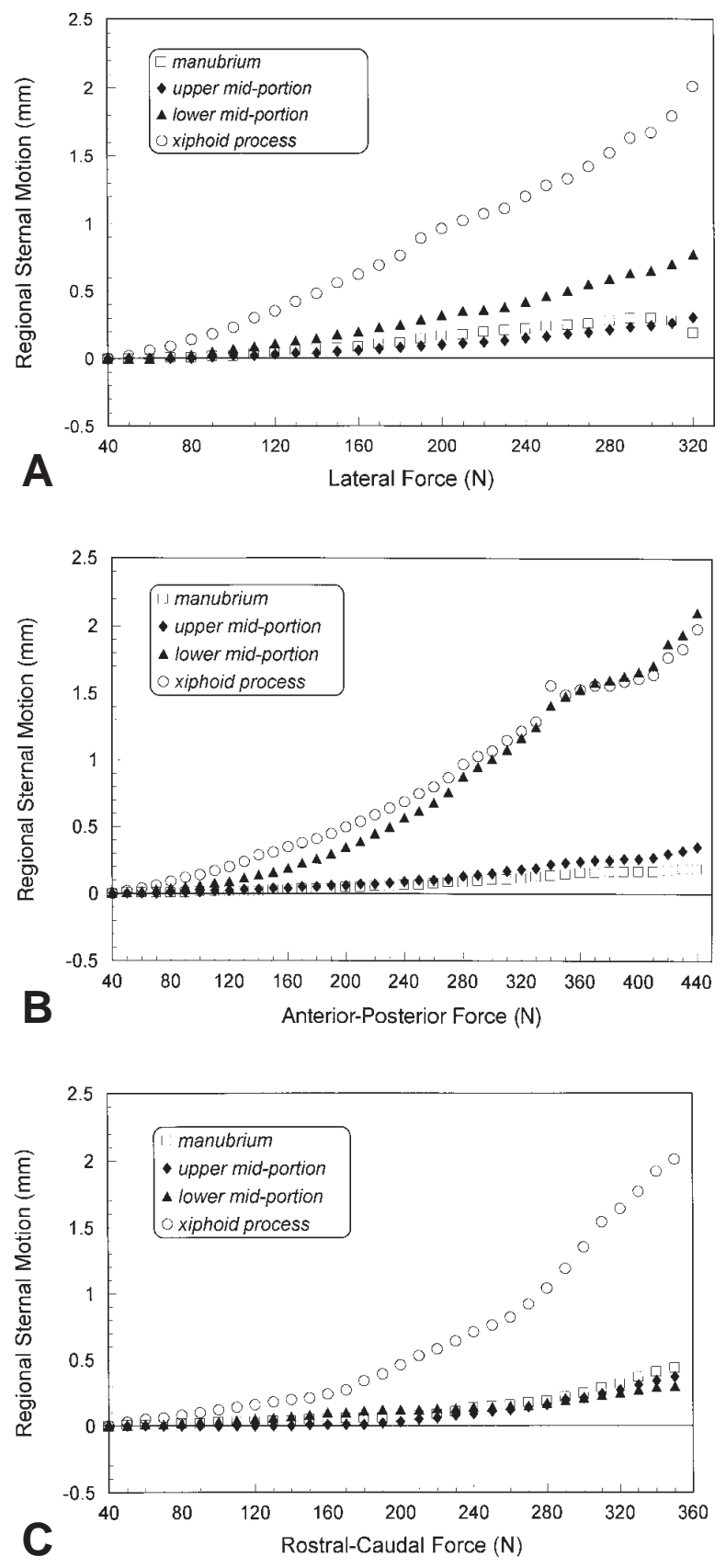

Fig 3. Regional sternal motion plotted against lateral (A), anterior-posterior (B), and rostral-caudal (C) traction forces. Open symbols represent the most cephalad and most caudal crystal pairs. Data are from the most robust model of sternal closure tested (male cadaver).

such as prolonged sternal pain or sternal non-union, or they can be catastrophic, such as sternal dehisence and mediastinitis. Most of the literature on sternal closure deals with patient-related factors that contribute to

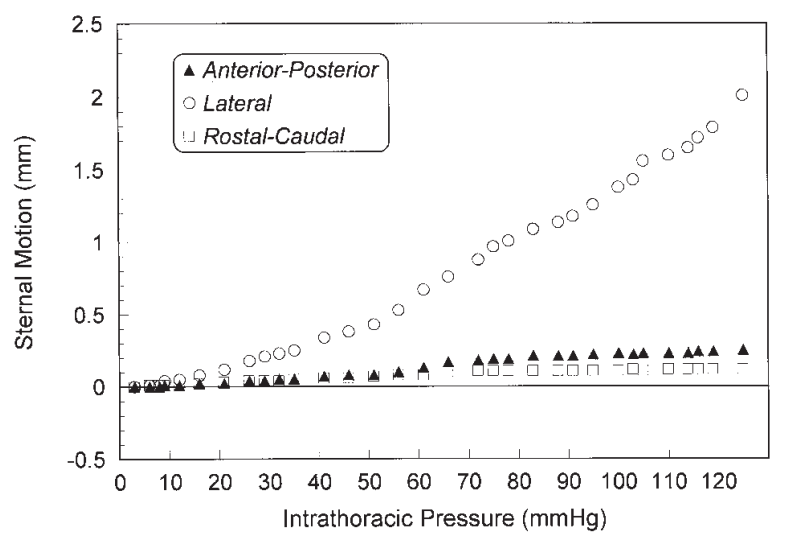

Fig 4. Sternal motion plotted against intrathoracic pressure during simulated Valsalva force. Open symbols represent the most cephalad and most caudal crystal pairs. Data are from the most robust model of sternal closure tested (male cadaver).

complications. Factors that have been implicated in sternal wound complications include obesity, insulindependent diabetes, chronic obstructive pulmonary disease, advanced age, and smoking. ${ }^{7-10}$ Other situations that increase the risk of sternal wound complications are operative or postoperative developments such as respiratory failure, low cardiac output states, and mediastinal re-exploration for bleeding. ${ }^{7,9,10}$

A number of papers have been published over the past 30 years that describe technical modifications intended to reduce sternal wound complications. Sternal and parasternal figure-of-eight wire arrangements ${ }^{11,12}$ along with the basket weave formation popularized by Robicsek, Daugherty, and Cook $^{13}$ are examples that use steel wire. Mechanical reinforcement of these closures may be achieved by simply uniting the pectoralis muscles over the sternum as described by Robicsek and Hamilton, ${ }^{14}$ such that contraction of these muscles serves to hold the sternal halves together rather than pull them apart. Others have used wider materials such as nylon bands, ${ }^{15}$ Mersilene ribbon ${ }^{16}$ (Ethicon, Inc, Somerville, NJ), and steel bands ${ }^{17}$ to accomplish wider force distribution. Nylon bands have subsequently been associated with a higher rate of sternal wound infection and are not recommended. ${ }^{18}$ Although clinical success with Mersilene ribbon and steel bands has been reported in prospective randomized studies, ${ }^{19,20}$ neither of these closure techniques has been widely accepted by the surgical community.

Steel wire remains popular because it is simple, inexpensive, and familiar. Sternal approximation is obtained by twisting the wire until an appropriate level of tension is felt by the surgeon. Because twisting 
weakens steel wire, some have recommended crimped metal sleeves ${ }^{21}$ or crimped metal plates ${ }^{22}$ to tighten and secure steel wire. Bench studies comparing twisted and crimped wire have demonstrated superior tensile strength with crimping. ${ }^{6}$ Our study, however, suggests that if crimped steel wire were tested in human sternums, the wire would tear through the bone before the crimping mechanism failed.

Only a few published studies have used an objective, biomechanical approach to analyze closure techniques. One such study, performed by Cheng and associates, ${ }^{23}$ compared different types of sternal closure in a human cadaver model. After sternotomy closure, the investigators removed the sternum, placed it in a biomechanical testing system, and measured motion that occurred under a lateral distracting force. They found the use of steel cerclage wiring to be a more stable closure method than those techniques that employ Mersilene ribbon or steel bands. Steel wire was superior because symmetric twisting allowed tension to be maintained across the sternal halves, resulting in snug approximation. In contrast, Mersilene ribbon required knot tying, which was not able to sustain adequate tension. Moreover, steel bands were too rigid to conform to the shape of the sternum, which precluded a secure fit. This important study provided direct visualization of different closure techniques under stress and allowed investigators to understand the flaws of some closure methods. However, limited explanation was given for the motion that occurred with cerclage steel wire closure.

A recent study by Ozaki and associates ${ }^{24}$ used methods similar to those of Cheng and colleagues to compare rigid plate and steel wire fixation in sternal closure. In the initial phase of the study, separation was seen to occur with both techniques when wires or plates pulled through the sternum. Subsequently, a new rigid plate technique was developed that effectively distributed force across the sternal closure and was more secure. By understanding the cause of closure instability (ie, closure material cutting through the sternum), the investigators were able to develop a better method for sternal closure. Surprisingly, few other studies have attempted to characterize instability after sternotomy closure.

This report presents an innovative approach to the analysis of sternal closure stability in that distracting forces are applied across the sternum with all anatomic support structures still intact. Because this experimental model subjects the intact human thorax to normal physiologic forces, it replicates real-life sternal stress distributions more accurately than is possible in sternums isolated from the rib cage and surrounding tis- sues. This whole-body experimental setup was used to test the adequacy of wire closure techniques, quantify the force levels required to disrupt the closure site, identify regions of poor sternal stability, and provide information concerning closure failure modes (eg, wire penetration into the bone, wire fracture, and twist-tie loosening) needed to design more reliable approximation methods.

Several findings from this study merit further discussion. First, significant amounts of sternal motion were detected with the application of physiologic force and pressure loads to the thoracic cage. It therefore seems likely that activities of daily life, such as pulling oneself up from a lying position or coughing, place significant strain on the sternal closure site, which can cause the sternal wires to cut into the sternum. This can lead to sternal pain in some cases and to sternal dehiscence in others. Second, traction forces were observed to cause more sternal distraction in the lateral direction than similar forces applied along other (orthogonal) lines of motion. In this study, forces required to distract the sternal halves in the lateral direction were smaller by $16 \%$ and $32 \%$, respectively, than those needed to move the sternum in the anterior-posterior and rostralcaudal directions. Likewise, modest intrathoracic pressures were seen to cause significant lateral separation of the sternal halves while producing little motion in the anterior-posterior and rostral-caudal directions. This in itself is not surprising, because only lateral separation can be achieved without the need to overcome bone-on-bone frictional forces, but these data are nonetheless important in establishing performance criteria for improved sternal closure methods. Finally, the areas of the sternum were not at equal risk for disruption. In each of these experiments, the lower half of the sternum was subject to more distraction than the manubrium. One possible explanation is that the manubrium is thicker than the lower sternum and may be stabilized by the clavicle, the more horizontal position of the ribs, and the relatively small volume of the upper thorax.

These data suggest that standard sternal closure methods for which multiple twisted wires are used may not always provide sufficient mechanical stability to allow proper wound healing, especially near the xiphoid. Perhaps the most obvious means to improve sternal stability (using this same closure technique) would be to simply secure an additional wire tie near the xiphoid process to further stabilize this portion of the sternum. The use of alternate weaving patterns such as the figure-of-eight technique could potentially enhance rostral-caudal stability but would be unlikely 
to reduce lateral instability caused by wire transmigration through the sternum. The addition of metal sleeves or grommets, acting in a manner analogous to shoelace eyelets, might be used to improve sternal stability by preventing the wire from cutting into the bone. Such reinforcements could also be used in conjunction with other wire closure techniques and would be especially important for older patients, in whom the sternum is thinner and more porous. We plan to test such reinforced wire closures, together with other closure techniques that similarly provide wider force distribution against the sternum (eg, basket weave, Mersilene ribbon, and steel banding) to quantify the degree to which sternal stability may be improved via these methods.

Experimental limitations. The use of embalmed cadavers can be considered a potential drawback because the mechanical properties of fixed tissues may differ from fresh bone and muscle. ${ }^{25,26}$ To address this concern, we performed identical tests on 2 female cadavers of similar size and age-one fixed with formaldehyde and the other fresh. Very similar results were seen in these 2 cadavers, suggesting that little practical difference exists between fixed and fresh sternums tested under quasistatic loading conditions. These results are consistent with findings by Currey and colleagues, ${ }^{27}$ who recently reported that similar tests on bovine bone were practically unaffected by formaldehyde fixation (although a significant decrease in impact strength was found).

Another factor separating this experimental model from actual clinical conditions is the time course of force application. Real-life sternal stresses tend to be transient in nature, lasting no more than a few seconds, whereas traction forces in this experiment were applied over more prolonged periods (15-20 seconds per force setting). Sternal motion, however, was seen to occur in discrete steps and in synchrony with force increases, indicating that wound separation can occur rapidly in response to modest traction forces. Still, force levels quoted here should be considered minimum values, recognizing that sternal closures may tolerate larger forces of very brief duration because of inertial damping effects.

\section{Conclusions}

Results from this study show that the traditional sternal closure technique with interrupted stainless steel wires does not always provide adequate fixation when the closure is subjected to physiologic mechanical stress. Improved closure methods should distribute the force of the closure over a larger surface area and provide firmer fixation of the lower aspect of the sternum, especially in relation to lateral stress. This model provides a means for scientific evaluation of both current sternal closure techniques and new methods designed to improve sternal stability and accelerate wound healing.

\section{REFERENCES}

1. Sanfelippo PM, Danielson GK. Complications associated with median sternotomy. J Thorac Cardiovasc Surg 1972;63:419-23.

2. Serry C, Bleck PC, Javid H, Hunter JA, Goldin MD, DeLaria GA. Sternal wound complications. J Thorac Cardiovasc Surg 1980;80: 861-7.

3. Ottino G, DePaulis R, Pansini S, Rocca G, Tallone MV, Comoglio C. Major sternal wound infection after open-heart surgery: a multivariate analysis of risk factors in 2,579 consecutive operative procedures. Ann Thorac Surg 1987;44:173-9.

4. Sarr MG, Gott VL, Townsend TR. Mediastinal infection after cardiac surgery (collective review). Ann Thorac Surg 1984;38:415-23.

5. Bitkover CY, Gardlund B. Mediastinitis after cardiovascular operations: a case-control study of risk factors. Ann Thorac Surg 1998;65:36-40.

6. Stoney WS, Alford WC Jr, Burrus GR, Frist RA, Thomas CS. Median sternotomy dehiscence. Ann Thorac Surg 1978;26:421-6.

7. Zacharias A, Habib RH. Factors predisposing to median sternotomy complications: deep vs. superficial infection. Chest 1996;110:1173-8.

8. Bryan AJ, Lamarra M, Angelini GD, West RR, Breckenridge IM. Median sternotomy wound dehiscence: a retrospective case control study of risk factors and outcome. J R Coll Surg Edinb 1992; 37:305-8

9. Demmy TL, Park SB, Liebler GA, Burkholder JA, Maher TD, Benckart DH, et al. Recent experience with major sternal wound complications. Ann Thorac Surg 1990;49:458-62.

10. Hazelrigg SR, Wellons HA Jr, Schneider JA, Kolm P. Wound complications after median sternotomy: relationship to internal mammary grafting. J Thorac Cardiovasc Surg 1989;98:1096-9.

11. Goodman G, Palatianos GM, Bolooki H. Technique of closure of median sternotomy with trans-sternal figure-of-eight wires. J Cardiovasc Surg 1986;27:512-3.

12. Taber RE, Madaras J. Prevention of sternotomy wound disruptions by use of figure-of-eight pericostal sutures. Ann Thorac Surg 1969;8:367-9.

13. Robicsek F, Daugherty HK, Cook JW. The prevention and treatment of sternum separation following open-heart surgery. J Thorac Cardiovasc Surg 1977;73:267-8.

14. Robicsek F, Hamilton DA. Presternal muscle padding following midline sternotomy. J Card Surg 1989;4:299-301.

15. LeVeen HL, Piccone VA. Nylon-band chest closure. Arch Surg 1968;96:36-9.

16. Johnston RH, Garcia-Rinaldi R, Vaughan GD, Bricker D. Mersilene ribbon closure of the median sternotomy: an improvement over wire closure. Ann Thorac Surg 1985;39:88-9.

17. Kalush SL, Bonchek LI. Peristernal closure of median sternotomy using stainless steel bands. Ann Thorac Surg 1976;21:172-3.

18. Sanfelippo PM, Danielson GK. Nylon band for closure of median sternotomy incisions: an unacceptable method. Ann Thorac Surg 1972;13:404-6.

19. Sirivella S, Zikria EA, Ford WB, Samadani SR, Miller WH, Sullivan ME. Improved technique for closure of median sternotomy incision. J Thorac Cardiovasc Surg 1987;94:591-5. 
20. Soroff HS, Hartman AR, Pak E, Sasvary DH, Pollack SB. Improved sternal closure using steel bands: early experience with three-year follow-up. Ann Thorac Surg 1996;61:1172-6.

21. Timmes JJ, Wolvek S, Fernando M, Bas M, Rocko J. A new method of sternal approximation. Ann Thorac Surg 1973;15:544-6.

22. Vincent JG. Update on sternal osteosynthesis. Ann Thorac Surg 1986;41:216-8.

23. Cheng W, Cameron DE, Warden KE, Fouger JD, Gott VL. Biomechanical study of sternal closure techniques. Ann Thorac Surg 1993;55:737-40.

24. Ozaki W, Buchman SR, Iannettoni MD, Frankenburg EP. Biomechanical study of sternal closure using rigid fixation techniques in human cadavers. Ann Thorac Surg 1998;65:1660-5.

25. Boskey AL, Cohen ML, Bullough PG. Hard tissue biochemisty: a comparison of fresh-frozen and formalin-fixed tissue samples. Calcif Tissue Int 1982;34:328-31.

26. Pleshko NL, Boskey AL, Mendelsohn R. An FT-IR microscopic investigation of the effects of tissue preservation on bone. Calcif Tissue Int 1992;51:72-7.

27. Currey JD, Brear K, Zioupos P, Reilly GC. Effect of formaldehyde fixation on some mechanical properties of bovine bone. Biomaterials 1995;16:1267-71. 